\title{
Research Article \\ Effect of Tracking Error of Double-Axis Tracking Device on the Optical Performance of Solar Dish Concentrator
}

\author{
Jian Yan $(\mathbb{D}$, Zi-ran Cheng, and You-duo Peng $\mathbb{1}$ \\ Hunan Provincial Key Laboratory of Health Maintenance for Mechanical Equipment, Hunan University of Science and Technology, \\ Xiangtan, Hunan 411201, China \\ Correspondence should be addressed to You-duo Peng; ydpeng@hnust.edu.cn
}

Received 25 July 2017; Revised 9 November 2017; Accepted 29 November 2017; Published 14 March 2018

Academic Editor: Alberto Álvarez-Gallegos

Copyright ( 2018 Jian Yan et al. This is an open access article distributed under the Creative Commons Attribution License, which permits unrestricted use, distribution, and reproduction in any medium, provided the original work is properly cited.

\begin{abstract}
In this paper, a flux distribution model of the focal plane in dish concentrator system has been established based on ray tracking method. This model was adopted for researching the influence of the mirror slope error, solar direct normal irradiance, and tracking error of elevation-azimuth tracking device (EATD) on the focal spot characteristics (i.e., flux distribution, geometrical shape, centroid position, and intercept factor). The tracking error transmission law of the EATD transferred to dish concentrator was also studied. The results show that the azimuth tracking error of the concentrator decreases with the increase of the concentrator elevation angle and it decreases to $0 \mathrm{mrad}$ when the elevation angle is $90^{\circ}$. The centroid position of focal spot along $x$-axis and $y$-axis has linear relationship with azimuth and elevation tracking error of EATD, respectively, which could be used to evaluate and calibrate the tracking error of the dish concentrator. Finally, the transmission law of the EATD azimuth tracking error in solar heliostats is analyzed, and a dish concentrator using a spin-elevation tracking device is proposed, which can reduce the effect of spin tracking error on the dish concentrator. This work could provide fundamental for manufacturing precision allocation of tracking devices and developing a new type of tracking device.
\end{abstract}

\section{Introduction}

Solar energy is a clean and environment-friendly renewable energy source, which is plentiful and can be widely distributed. Developing and utilizing solar energy are important ways to solve energy shortages and environmental pollution problems, for example, the $\mathrm{H}_{2}$ production by solar thermochemical reactions [1], solar cooker [2], and solar energy thermal electric power system [3]. Among all those typical solar energy applications in medium-high temperature fields, the solar concentrator was commonly used in the abovementioned fields to collect the sunlight as heat source and provide heat source to the heat receiver because the solar radiation density received by the earth surface was low. There are four main types of solar concentrators: Fresnel concentrator $[4,5]$, parabolic trough concentrator $[6,7]$, tower heliostat $[8,9]$, and parabolic dish concentrator [10-12]. The singledish concentrator could realize the high concentration ratio and high temperature so it is superior to other concentrators. Typical application, such as the solar dish concentrator photovoltaic system and the dish-Stirling solar power system, consists of a dish concentrator and a Stirling engine [10] such as the $38 \mathrm{~kW}$ XEM-Dish system as shown in Figure 1.

The dish concentrator via an elevation-azimuth doubleaxis tracking device (EATD) was used to accurately track the sun's position so it could focus the sunlight to the precalculated position of the receiver [10-12]. The EATD consists of an elevation tracking device and an azimuth tracking device (Figures 1(b) and 1(c)), which is widely used in dishconcentrating system. The azimuth tracking axis in EATD is vertical to the ground level, and the elevation tracking axis in EATD is parallel to the ground level and vertical to the focal axis of a dish concentrator. The program tracking process of a dish concentrator system is as follows: calculate the position information of the sun (the elevation angle and azimuth angle of the sun) by astronomical algorithm [13]; according to the sun position information, the output rotation angle of an azimuth motor and elevation motor in the EATD is controlled and then the elevation tracking axis $\mathbf{n}_{1}$ and azimuth tracking axis $\mathbf{n}_{2}$ in the EATD can rotate a 


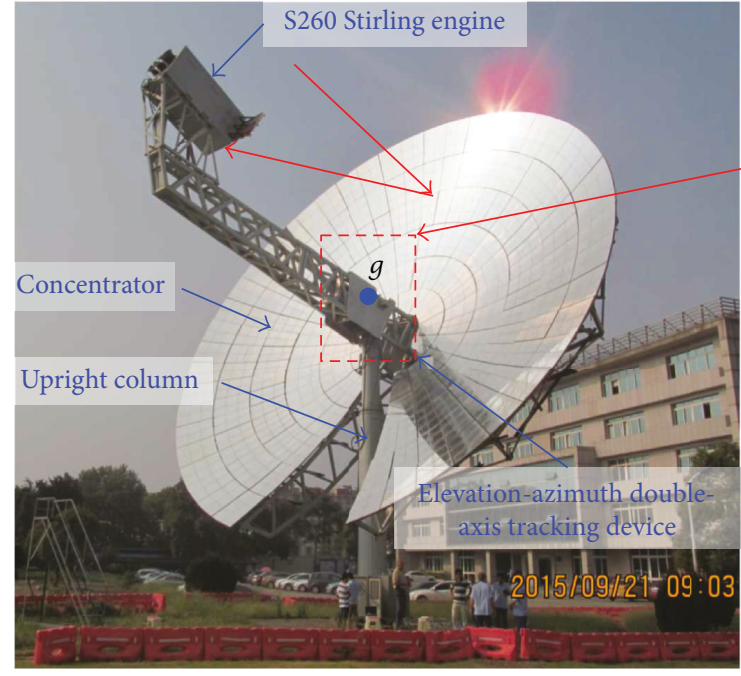

(a)

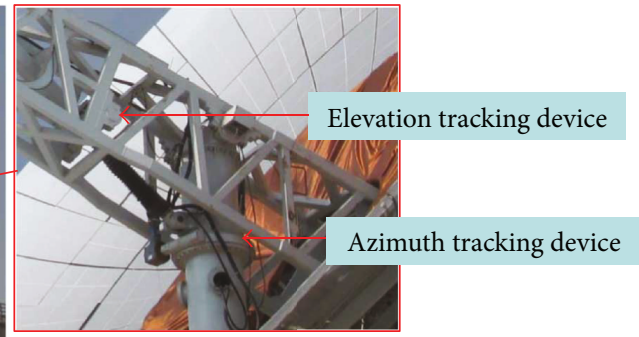

(b)

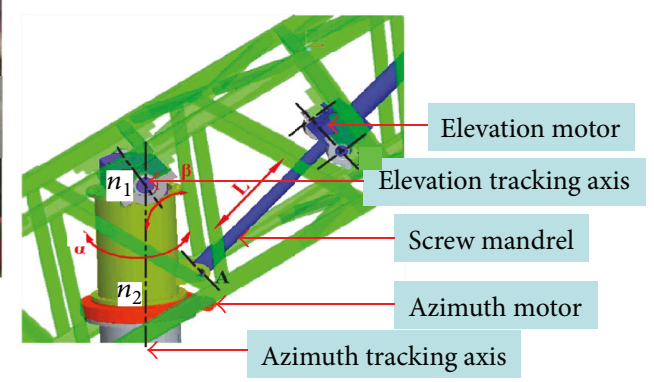

(c)

FIgURE 1: A $38 \mathrm{~kW}$ dish-Stirling solar thermal power system (38 $\mathrm{kW}$ XEM-Dish system). The diameter is $17.70 \mathrm{~m}$ and the focal length is $9.49 \mathrm{~m}$ of the parabolic dish concentrator and was built in Xiangtan Electric Manufacturing Group, China.

corresponding angle (Figure 2(b)), which will change the azimuth and elevation angle of the dish concentrator for realizing the focal axis aiming at the sun's center. Therefore, the tracking accuracy of a dish concentrator could be influenced by astronomical algorithm, driving error of the motor and EATD, installation error of the EATD, and so on, where driving error of the EATD is the main factor (i.e., output rotation angle error of the azimuth and elevation tracking axis in the EATD, called EATD tracking error). The EATD tracking error could lead the dish concentrator to produce tracking error so it would cause some adverse phenomenon, such as the optical losses and nonuniform flux in the receiver. Thus, improving the tracking accuracy of a dish concentrator and reducing the manufacturing precision requirement of the EATD (i.e., reducing the manufacturing cost) have always been the pursuit of commercial applications. Therefore, researching the influence of the EATD tracking error on the tracking performance and optical performance of dish concentrator system is very important.

Many works focus on the research for the influence of tracking error on the optical performance or flux distribution of dish concentrator system [14-21], but they do not consider the influence of EATD tracking error. Hughes [14] used statistical methods to establish an expression for the expected value of the intercept factor for various configurations and control law implementations. The analysis assumes that a radially symmetric flux distribution is generated at the focal plane. Badescu [15] researched the different tracking error distributions and their effects on the long-term performances of parabolic dish solar power systems; he adopted four different tracking error distributions to evaluate the intercept factor and the thermal and engine efficiencies, three of them are bounded distributions and the last one is the widely used classical Gaussian distribution. Further, he also studied the theoretical derivation of heliostat tracking error distribution using methods of integral geometry and geometrical probabilities [16]. Hu and Yao used MCRT method to research the flux distribution on the solar cell plane in a two-stage concentration photovoltaic system with concentrator tracking error (dish concentrator is the first level) [17]. Shanks et al. [18] researched the flux distribution and optical efficiency in a high-concentrating photovoltaic system with concentrator tracking error (using the Cassegrain concentrator). Xia et al. [19] researched the influence of the concentrator tracking error on the intercept factor of a sixteen-dish concentrator. Li et al. [20] and Castellanos et al. [21] through the theoretical model research the influence of the total optical error on the intercept factor in the dish concentrator system. In the experimental measurement, the measured results of the flux distribution on the focal plane have been widely used to evaluate the surface slope error, tracking error, and optical efficiency of the dish concentrator system [19, 22, 23], which could also be used for adjusting the tracking error of dish concentrators. For example, Johnston [22] developed a flux mapping equipment and measured the flux distribution on the focal plane of a $20 \mathrm{~m}^{2}$ dish concentrator. This concentrator mirror slope error has been determined is $2.0 \mathrm{mrad}$. Xia et al. [19] developed a type of concentrated solar flux distribution measurement formed by a thermal infrared imager and water-cooled Lambert target and measured the flux distribution on the focal plane of a sixteen-dish concentrator. Through the comparison of the measured results and ray tracking calculation results of the flux distribution, they determined the concentrator mirror slope error is $2.2 \mathrm{mrad}$ and concentrator total tracking error is $0.8 \mathrm{mrad}$. But the single tracking error of the concentrator has not been analyzed in their paper. The measured results of the flux distribution on the focal plane of the dish concentrator could be used to 


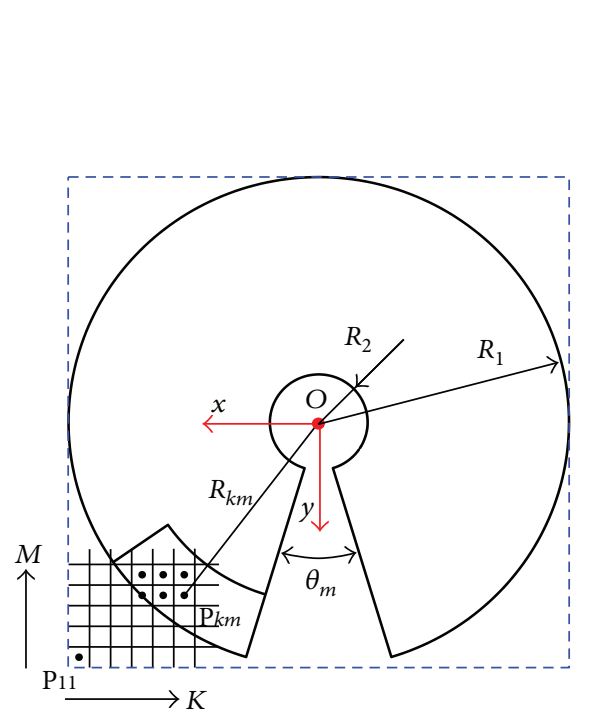

(a)

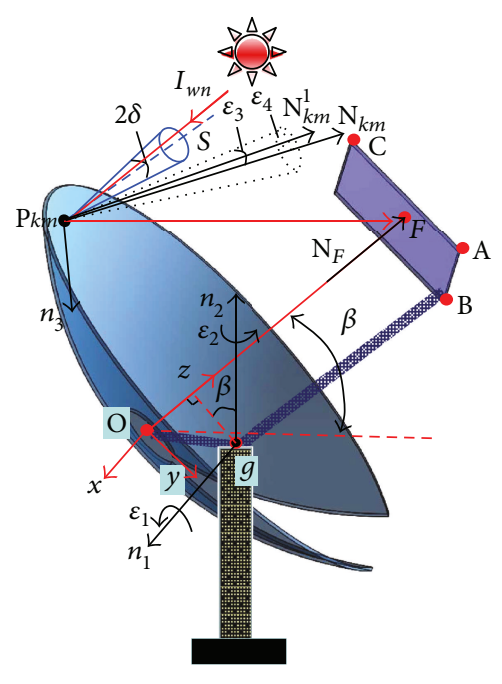

(b)

FIGURE 2: (a) Geometry parameters and mirror discrete of the dish concentrator and (b) schematic diagram of the tracking error and mirror slope error of the dish concentrator.

evaluate or calibrate the tracking error of the dish concentrator. But this process would be influenced by the concentrator mirror slope error and solar direct normal irradiance (DNI), which would change the geometry shape or flux distribution of the focal spot on the focal plane $[24,25]$. Therefore, it is necessary to find a new focal spot characteristic to establish the functional relationship between the focal spot characteristic and tracking error of dish concentrator to realize the evaluation and calibration of concentrator tracking error.

The above-mentioned literatures all focus on the influence of the total tracking error of dish concentrator systems on the flux distribution and optical performance, while the researches of the influence of the tracking error of the EATD on the tracking performance and optical performance of dish concentrator system are limited. In this paper, we focused on the above two aspects; a flux distribution model of the focal plane in dish concentrator systems has been established based on ray tracking method. The concentrator mirror and solar cone in nonuniform energy distribution are discreted by square grids in this model (in Section 2). This model was adopted for researching the influence of the mirror slope error and DNI and EATD tracking error on the focal spot characteristics (i.e., flux distribution, geometrical shape, centroid position, and intercept factor), and the tracking error transmission law of the EATD transferred to dish concentrator was studied (in Section 4). Moreover, the transmission law of the EATD azimuth tracking error in solar heliostats is analyzed, a dish concentrator system using a spin-elevation double-axis tracking device is proposed, and the transmission law of the tracking error from the spin axis to the dish concentrator was studied (in Section 4.4). This work could provide fundamental for calibrating the tracking error of dish concentrator system, manufacturing precision allocation of a double-axis tracking device (appropriately decrease the manufacturing precision of the azimuth or spin tracking device), and developing a new type of tracking device.

\section{Mathematical Model}

The flux distribution model of the plane receiver in dish concentrator systems is developed based on the ray tracking method. The ray tracking method needs to discrete the mirror surface of dish concentrators, plane receiver, and sun cone. There are two methods to discrete the mirror surface and sun cone, a random MCRT method $[4,12]$ and a grid discrete method [26]. In this work, we adopted the grid discrete method to establish the sun cone discretization model considering a nonuniform energy distribution and flux distribution model of the focal plane in dish concentrator systems (i.e., optical model). The mirror slope error of the dish concentrator and tracking error of the EATD are included in this optical model.

2.1. Optical Model. As shown in Figure 2, a coordinate system $\mathrm{O}-x y z$ was built on the vertex point $O$ of a parabolic mirror surface and the $z$-axis points to the focal point $F$. The mirror surface function of a dish concentrator can be defined as $x^{2}+y^{2}=4 f z$, where $f$ is the focal length of the dish concentrator. In Figure 2(a), $R_{1}$ is aperture radius of the dish concentrator, and angle $\theta_{\mathrm{m}}$ and radius $R_{2}$ are no mirror area in the dish concentrator. The steps for optical discretization of the dish concentrator are as follows: (1) use a square with side length of $2 R_{1}$ (blue wire frame in Figure $2(\mathrm{a})$ ) to surround the dish concentrator mirror and then the discrete into a lot of square grid with side length of $2 R_{1} / K(M=K$, i.e., the daylighting area $A_{k m}$ of each grid is equal, $\left.A_{k m}=\left(2 R_{1} / K\right)^{2}\right)$; (2) according to the coordinate and distance $R_{k m}$ of the point $\mathrm{p}_{k m}$ (i.e., grid center point in $k$ line $m$ column) to determine whether the grid $\mathrm{km}$ is in the reflection mirror. If the point $\mathrm{p}_{k m}$ is in the reflection mirror, the identifier $f_{k m}=1$ (i.e., the grid $\mathrm{km}$ is effective); otherwise, $f_{\mathrm{km}}=0$ (i.e., the grid $\mathrm{km}$ is a noneffective); (3) the coordinates and unit normal vector $\mathbf{N}_{k m}$ of the center point $\mathrm{p}_{k m}$ of all effective grid are calculated and stored for subsequent ray tracing simulation. 
In practical application, the reflection mirror of a dish concentrator would have microslope error, which would impact the normal vector of the reflection mirror (Figure 2(b)). The mirror slope error could be described as a radial angle $\varepsilon_{3}$ and tangential angle $\varepsilon_{4}[17,24]$ :

$$
\begin{aligned}
& \varepsilon_{3}=\sqrt{\left(-2 \sigma^{2}\right) \ln r_{1}}, \\
& \varepsilon_{4}=2 \pi r_{2}
\end{aligned}
$$

where $r_{1}$ and $r_{2}$ are uniformly distributed random numbers within the range of $0 \sim 1, \sigma$ is standard deviation of the mirror slope error.

Considering the mirror slope error of the dish concentrator, the vector $\mathbf{N}_{k m}^{1}$ on point $\mathrm{p}_{k m}$ is calculated by (2), where $\operatorname{Rot}\left(n_{3}, \varepsilon_{3}\right)$ and $\operatorname{Rot}\left(\mathbf{N}_{k m}, \varepsilon_{4}\right)$ are mirror slope error matrix which could all be determined by function $\operatorname{Rot}(e, \beta)$ as shown in (3). $\boldsymbol{R o t}(e, \beta)$ could be used to realize the vector $\mathbf{P}$ $\in \mathbf{R}^{1 \times 3}$ rotate $\beta$ angle around the unit vector $\mathbf{e}=\left[e_{x}, e_{y}, e_{z}\right]$; $n_{3}=\left(\mathbf{N}_{k m} \times e_{x}\right) /\left|\mathbf{N}_{k m} \times e_{x}\right| ; e_{x}=[1,0,0]$.

$$
\begin{aligned}
\mathbf{N}_{k m}^{1} & =\mathbf{N}_{k m} \cdot \operatorname{Rot}\left(n_{3}, \varepsilon_{3}\right) \cdot \operatorname{Rot}\left(\mathbf{N}_{k m}, \varepsilon_{4}\right) \\
\operatorname{Rot}(\mathbf{e}, \beta) & =\left[\begin{array}{ccc}
\cos \beta+e_{x}^{2}(1-\cos \beta) & e_{x} e_{y}(1-\cos \beta)+e_{z} \cdot \sin \beta & e_{x} e_{z}(1-\cos \beta)-e_{y} \cdot \sin \beta \\
e_{x} e_{y}(1-\cos \beta)-e_{z} \cdot \sin \beta & \cos \beta+e_{y}^{2}(1-\cos \beta) & e_{y} e_{z}(1-\cos \beta)+e_{x} \cdot \sin \beta \\
e_{x} e_{z}(1-\cos \beta)+e_{y} \cdot \sin \beta & e_{y} e_{z}(1-\cos \beta)-e_{x} \cdot \sin \beta & \cos \beta+e_{z}^{2}(1-\cos \beta)
\end{array}\right] .
\end{aligned}
$$

In ideal tracking condition, the focal axis of the dish concentrator is parallel to the center line $S(S=[0,0,-1.0])$ in the sun cone (sun half-apex angle $\delta=4.65 \mathrm{mrad}$ ). However, when the EATD exists tracking error (elevation and azimuth tracking error of the EATD is $\varepsilon_{1}$ and $\varepsilon_{2}$, respectively, Figure 2(b)); the point $p_{k m}$ moving to the position $p_{k m}^{1}$ and the corresponding normal vector is $\mathbf{N}_{k m}^{2}$. As well as the included angle $\omega_{\text {err }}$ between the focal axis of the dish concentrator and center line $S$ in sun cone, this angle $\omega_{\text {err }}$ is the total tracking error of the dish concentrator. This could be calculated by (4), (5), (6), (7), where $\mathbf{n}_{1}$ is elevation tracking axis vector of the EATD, $\mathbf{n}_{1}=[1,0,0] ; \mathbf{n}_{2}$ is the azimuth tracking axis vector of the EATD, $\mathbf{n}_{2}=[0,-\cos \beta, \sin \beta]$; the angle $\beta$ is solar elevation angle (i.e., working elevation angle of the dish concentrator); $g$ is a position vector of the crosspoint $g$ of the elevation tracking axis and azimuth tracking axis in the EATD (Figures 1 and 2(b)), $\mathbf{g}=[0, g y, g z]$. Noteworthiness, the tracking error of the dish concentrator originated in the EATD tracking error. This tracking error transmission related to the working elevation angle $\beta$ of the dish concentrator, which could be clearly seen in (6).

$$
\begin{aligned}
p_{k m}^{1}= & \left(p_{k m}-\mathbf{g}\right) \cdot \operatorname{Rot}\left(\mathbf{n}_{1}, \varepsilon_{1}\right) \cdot \operatorname{Rot}\left(\mathbf{n}_{2}, \varepsilon_{2}\right)+\mathbf{g}, \\
\mathbf{N}_{k m}^{2}= & \mathbf{N}_{k m}^{1} \cdot \operatorname{Rot}\left(\mathbf{n}_{1}, \varepsilon_{1}\right) \cdot \operatorname{Rot}\left(\mathbf{n}_{2}, \varepsilon_{2}\right) \\
\mathbf{N}_{\mathrm{F}}^{1}= & \mathbf{N}_{\mathrm{F}} \cdot \operatorname{Rot}\left(\mathbf{n}_{1}, \varepsilon_{1}\right) \cdot \operatorname{Rot}\left(\mathbf{n}_{2}, \varepsilon_{2}\right) \\
\omega_{\mathrm{err}}\left(\varepsilon_{1}, \varepsilon_{2}, \beta\right)= & \operatorname{arcos}\left[\sin \left(\varepsilon_{1}+\beta\right) \cdot \sin \beta \cdot\left(1-\cos \varepsilon_{2}\right)\right. \\
& \left.+\cos \varepsilon_{1} \cdot \cos \varepsilon_{2}\right]
\end{aligned}
$$

When the dish concentrator system exists tracking error, the plane receiver (located at the focal plane of dish concentrators) would rotate with the dish concentrator. This time, the focal point $F$ moves to position $\mathbf{F}_{1}$ and the corresponding plane receiver normal vector is $\mathbf{N}_{F}^{1}$, which can be calculated by (8) and (6), respectively, where $\mathbf{F}=[0,0, f]$. These two vectors can determine the space equation of the plane receiver.

$$
\mathbf{F}_{1}=(\mathbf{F}-\mathbf{g}) \cdot \boldsymbol{\operatorname { R o t }}\left(\mathbf{n}_{1}, \varepsilon_{1}\right) \cdot \boldsymbol{\operatorname { R o t }}\left(\mathbf{n}_{2}, \varepsilon_{2}\right)+\mathbf{g} .
$$

In this work, the plane receiver is a square with side length is $L$, which can be discreted into a lot of square grid (discrete parameter $H=U$ ). The calculation process of the flux distribution on the plane receiver as is as follows: (1) based on the law of specular reflection, the reflected ray equation of the incident sunlight $I_{\mathrm{wn}}$ on the mirror point $p_{\mathrm{km}}^{1}$ is calculated by (4) and (5); (2) the intersection point $q$ of the reflected ray and plane receiver is calculated, $\mathbf{q}=\left[x_{1}, y_{1}, z_{1}\right]$; (3) the grid number $h u$ containing point $q$ is found and then increasing the sunlight $I_{\mathrm{wn}}$ carrying energy (Section 2.2) to the grid $h u$; (4) following these steps, calculating every effective grid in the dish concentrator whole sunlight transmission process could get the flux distribution results on the plane receiver.

2.2. Discretization Model of the Sun Cone. The solar radiation intensity in a sun cone gradually decreases from the center to the border. The nonuniform energy distribution model is given as [27]:

$$
I(\gamma)= \begin{cases}I_{1}\left[1-0.5138\left(\frac{\gamma}{\delta}\right)^{4}\right], & 0 \leq \gamma \leq \delta, \\ 0, & \gamma>\delta,\end{cases}
$$

where $\gamma$ is the intersection angle of the discrete ray and center ray $S$ (Figure 3 ); $I_{1}$ is the radiation intensity of the center ray.

The sun cone received by different positions in the dish concentrator mirror was assumed to be exactly identical. Thus, the sun cone was established on the point $O$ and discretization as shown in Figure 3(b). In details, the solar disk on the focal plane was established (the radius is $R_{\mathrm{s}}, R_{\mathrm{s}}=f \times \tan (\delta)$ ) 


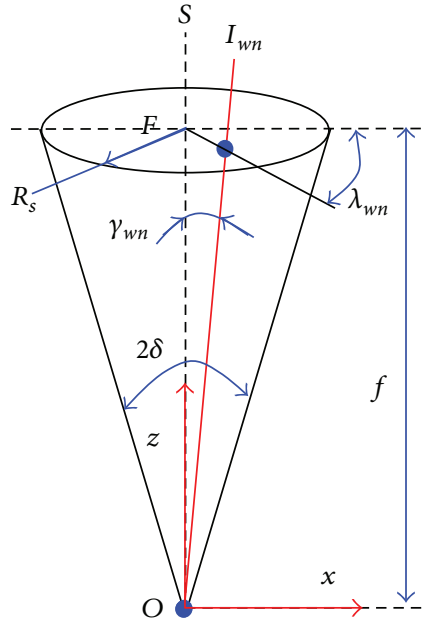

(a)

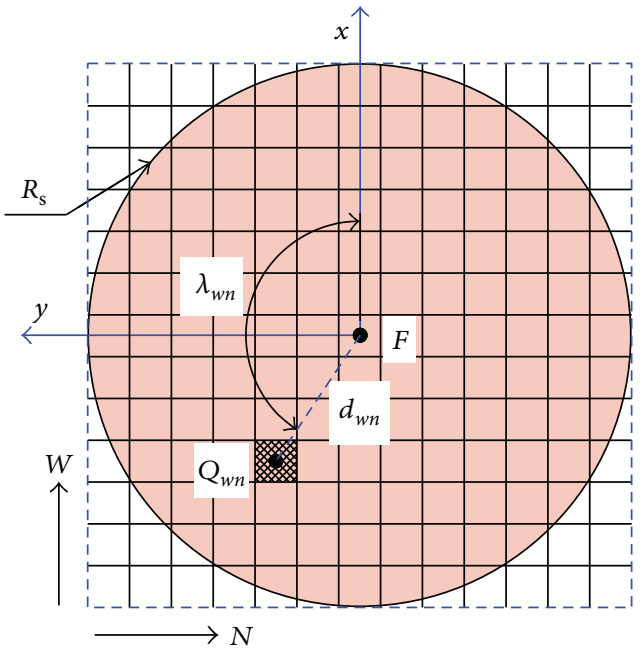

(b)

Figure 3: Discretization of the (a) sun cone and (b) solar disk.

and it adopts the square envelope and then discrete to square grid $(W=N)$. Thus, the position vector of the point $\mathbf{Q}_{w n}$ is

$$
\mathbf{Q}_{w n}=\left[(w-0.5) \frac{2 R_{s}}{W}-R_{s}, R_{s}-(n-0.5) \frac{2 R_{s}}{N}, f\right] .
$$

Based on the principle of energy conservation equation, the dish concentrator and sun cone before and after the discretization should satisfy the following relationship:

$$
\begin{aligned}
& A_{\text {dish }} \cdot W_{0}= \sum_{k=1}^{K} \sum_{m=1}^{M}\left(f_{k m} \cdot A_{k m} \cdot e_{0}\right) \\
&= \sum_{k=1}^{K} \sum_{m=1}^{M}\left\{f_{k m} \cdot A_{k m} \cdot \sum_{w=1}^{W} \sum_{n=1}^{N} f_{w n} \cdot I_{1}\right. \\
&\left.\cdot\left[1-0.5138\left(\frac{\gamma_{w n}}{\delta}\right)^{4}\right]\right\},
\end{aligned}
$$

where $e_{0}$ is the radiation intensity of a single sun cone; $\gamma_{w n}=\arctan \left(d_{w n} / f\right)$ is the intersection angle of the sunlight ray $w n$ and central sunlight; $d_{w n}=\left\|\mathbf{Q}_{w n}-\mathbf{F}\right\| ; W_{0}$ is the DNI value $\left(\mathrm{W} / \mathrm{m}^{2}\right) ; A_{\text {dish }}=\sum_{k=1}^{K} \sum_{m=1}^{M}\left(f_{k m} \cdot A_{k m}\right)$ is aperture total area of the dish concentrator. If $d_{w n} \leq R_{s}, f_{w n}=1$; if $d_{w n}>R_{s}, f_{w n}=0$. Thus, $I_{1}$ can be written as follows:

$$
I_{1}=\frac{W_{0}}{\sum_{\mathrm{w}=1}^{W} \sum_{n=1}^{N} f_{w n}\left[1-0.5138\left(\gamma_{w n} / \delta\right)^{4}\right]} .
$$

Finally, the sunlight vector $\mathbf{I}_{w n}=-\mathbf{Q}_{w n} /\left\|\mathbf{Q}_{w n}\right\|$ and the energy carried by the sunlight can be determined by (9) and (12).

2.3. Model Validation. Based on the optical model and sun cone model in this paper, the ray tracing codes were compiled in Visual C++ 6.0 software for calculating the flux distribution on the focal plane of the dish concentrator. The Jeter theoretical results [28] were adopted to check the validity of the optical model and ray tracing codes and the comparison results as shown in Figure 4(a). We can see that the ray tracing calculation results in good agreement to Jeter's theoretical results, which verifies the validity of the flux distribution model in this paper. The flux distribution contour map calculated by ray tracing method in this paper is shown in Figure 4(b).

\section{Focal Spot Characterization}

Due to the reason that the tracking error of the EATD would cause the tracking error of the dish concentrator, the position and geometry of the focal spot on the plane receiver would all change. The focal spot moves and extends to the upper right direction, and the flux contour is approximately ellipse shaped but the center position of the ellipse is different, such as in Figure 5. In this paper, using a flux distribution map, flux distribution curve along the $x$-axis and $y$-axis, intercept factor, centroid position, and ellipse geometry (a flux contour curve) are used to describe the focal spot. Where centroid position and ellipse geometry could describe the movement direction and geometrical extent of the focal spot, respectively.

The intercept factor is defined as the ratio of the energy on the plane receiver (radius is $R_{\text {in }}$ ) to the total received energy $[14,19]$. The centroid coordinates of the focal spot could be calculated by $(13)$, where $f(h, u)$ is the flux density of the grid $h u$ on the plane receive. Ellipse equation as shown in (14), including five parameters: center point coordinate $s\left(x_{s}, y_{s}\right)$, minor semiaxis $b$, major semiaxis $a$, and intersection angle $\phi_{2}$ with the major axis and axis $x_{1}$. The grid of the flux density equal or approaching to $C_{\mathrm{t}} \times W_{0}$ was found on the receiver and then the center point coordinates of the grid were extracted (as the ellipse boundary point) for fitting (16) to get the ellipse parameters using the least square method $\left(C_{t}\right.$ is a flux density extraction threshold value). The searching process of the ellipse boundary point is that according to the plane receiver discrete grid, from top to bottom ( $y$-axis direction), to find the two adjacent grid for the first time, satisfy $f(h, u) \leq C_{\mathrm{t}} \cdot W_{0} \leq f(h, u+1)$. Then we selected one grid center as the boundary point (i.e., ellipse 


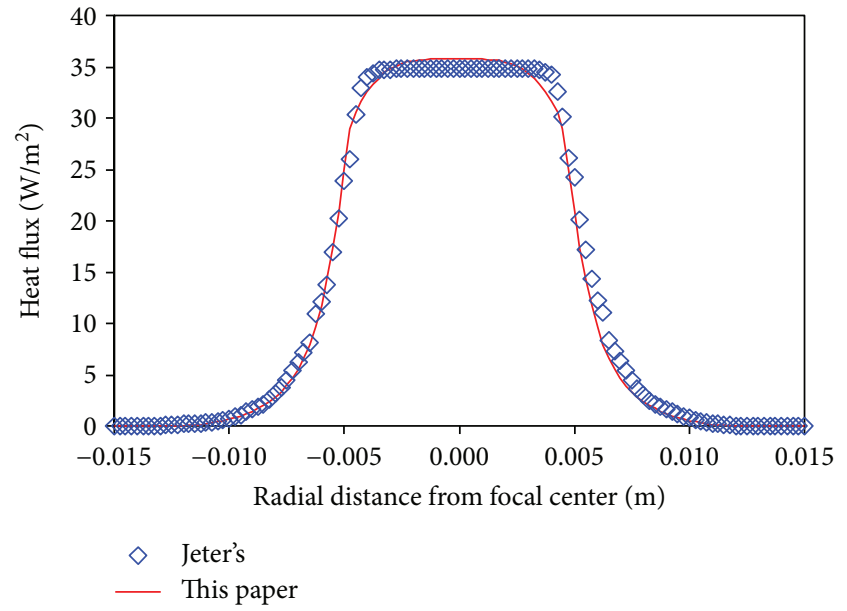

(a)

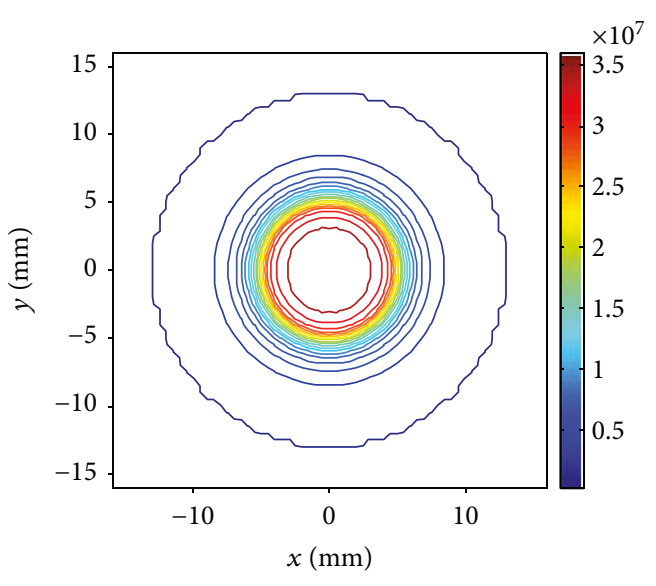

(b)

Figure 4: (a) The comparison of the flux distribution result on the focal plane and (b) flux distribution contour map using ray tracing method in this paper $\left(\mathrm{W} / \mathrm{m}^{2}\right)$.

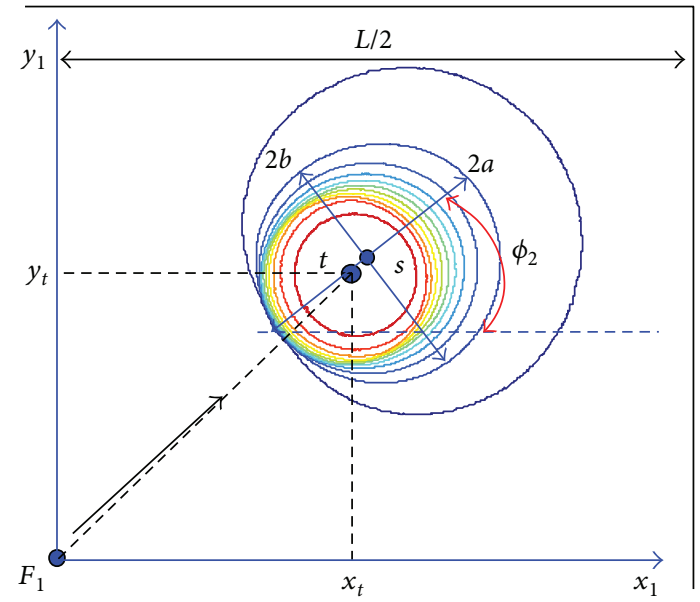

Figure 5: Geometrical parameters of the focal spot on the plane receive.

up boundary point) which is the flux density closest to the $C_{t} \times W_{0}$. In the same way, from bottom to the top to find the ellipse bottom boundary point.

$$
\begin{aligned}
& x_{t}=\frac{\sum_{h=1}^{H} \sum_{u=1}^{U} f(h, u) \cdot(u-0.5)(L / U)}{\sum_{h=1}^{H} \sum_{u=1}^{U} f(h, u)}, \\
& y_{t}=\frac{\sum_{h=1}^{H} \sum_{u=1}^{U} f(h, u) \cdot(h-0.5)(L / U)}{\sum_{h=1}^{H} \sum_{u=1}^{U} f(h, u)}, \\
& \frac{\left[\left(x-x_{s}\right) \cos \phi_{2}+\left(y-y_{s}\right) \sin \phi_{2}\right]^{2}}{a^{2}} \\
& +\frac{\left[\left(y-y_{s}\right) \cos \phi_{2}-\left(x-x_{s}\right) \sin \phi_{2}\right]^{2}}{b^{2}}=1 .
\end{aligned}
$$

\section{Result and Discussion}

4.1. Concentrator Tracking Error. The tracking error of the EATD would cause the tracking error of the dish concentrator, but the tracking error of the dish concentrator may not be equal to the tracking error of the EATD. This tracking error transmission (i.e., tracking error of the EATD transmitted to dish concentrator) is related to the working elevation angle $\beta$ of the dish concentrator. In Figure 6, when the EATD only has azimuth tracking error, the total tracking error $\omega_{\text {err }}$ of the dish concentrator decreases with the increase of elevation angle $\beta$ and the error $\omega_{\text {err }}$ decreases to $0 \mathrm{rad}$ when the angle $\beta$ is $90^{\circ}$ (curve $1 \sim 5$ in Figure $6(\mathrm{a})$ ). When the EATD has both elevation and azimuth tracking error, the error $\omega_{\text {err }}$ decreases with the increase of the elevation angle $\beta$ and the error $\omega_{\text {err }}$ is equal to the elevation tracking error $\varepsilon_{1}$ of the EATD when the angle $\beta$ is $90^{\circ}$, which could be clearly seen in Figure 6(a) (curve 7 11) and Figure 6(b). That is to say, the increase of the working elevation angle $\beta$ of the dish concentrator would vanish or reduce the influence from the azimuth tracking error of the EATD to the dish concentrator. This phenomenon is called vanish-reduction effect in tracking error transmission by us. However, the elevation tracking error of the EATD transmit to the dish concentrator has no vanish-reduction effect, that is, the elevation tracking error of the dish concentrator equal to the elevation tracking error of the EATD. Thus, the concentrator total tracking error in (6) can be rewritten as follows:

$$
\begin{aligned}
\omega_{\mathrm{err}}( & \left.\varepsilon_{1}, \varepsilon_{2}, \beta\right) \\
& =\sqrt{\left(\varepsilon_{2 r}\right)^{2}+\left(\varepsilon_{1}\right)^{2}} \\
& =\sqrt{\left(\operatorname{arcos}\left[(\cos (90-\beta))^{2} \cdot\left(1-\cos \varepsilon_{2}\right)+\cos \varepsilon_{2}\right]\right)+\left(\varepsilon_{1}\right)^{2}},
\end{aligned}
$$

where $\varepsilon_{2 r}$ is azimuth tracking error of the dish concentrator from the azimuth tracking error $\varepsilon_{2}$ of the EATD. 


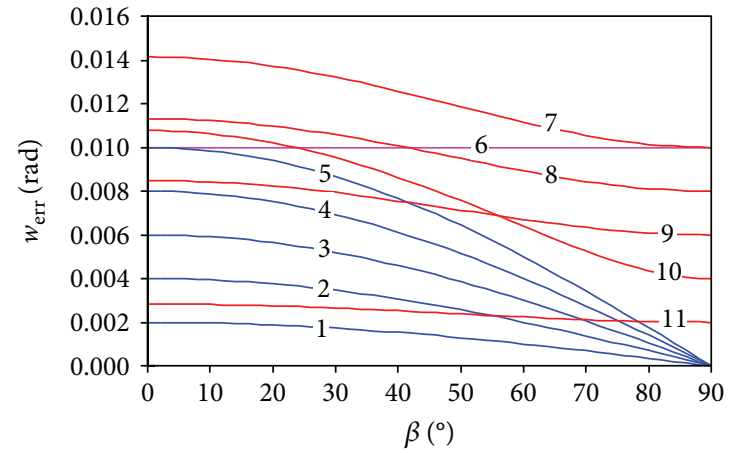

(a)

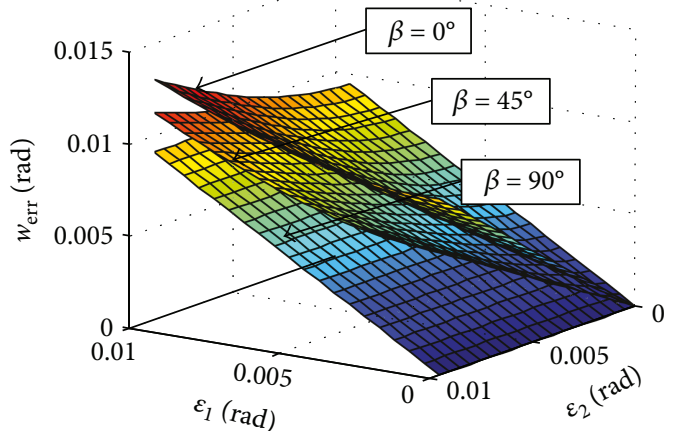

(b)

FIGURE 6: Influence of the tracking error of the EATD on the dish concentrator. 1: $\varepsilon_{1}=0 \mathrm{mrad}, \varepsilon_{2}=2 \mathrm{mrad} ; 2: \varepsilon_{1}=0 \mathrm{mrad}, \varepsilon_{2}=4 \mathrm{mrad} ; 3$ : $\varepsilon_{1}=0 \mathrm{mrad}, \varepsilon_{2}=6 \mathrm{mrad} ; 4: \varepsilon_{1}=0 \mathrm{mrad}, \varepsilon_{2}=8 \mathrm{mrad} ; 5: \varepsilon_{1}=0 \mathrm{mrad}, \varepsilon_{2}=10 \mathrm{mrad} ; 6: \varepsilon_{1}=10 \mathrm{mrad}, \varepsilon_{2}=0 \mathrm{mrad} ; 7: \varepsilon_{1}=10 \mathrm{mrad}, \varepsilon_{2}=10 \mathrm{mrad}$; 8: $\varepsilon_{1}=8 \mathrm{mrad}, \varepsilon_{2}=8 \mathrm{mrad}$; 9: $\varepsilon_{1}=6 \mathrm{mrad}, \varepsilon_{2}=6 \mathrm{mrad} ; 10: \varepsilon_{1}=4 \mathrm{mrad}, \varepsilon_{2}=10 \mathrm{mrad} ; 11: \varepsilon_{1}=2 \mathrm{mrad}, \varepsilon_{2}=2 \mathrm{mrad}$.

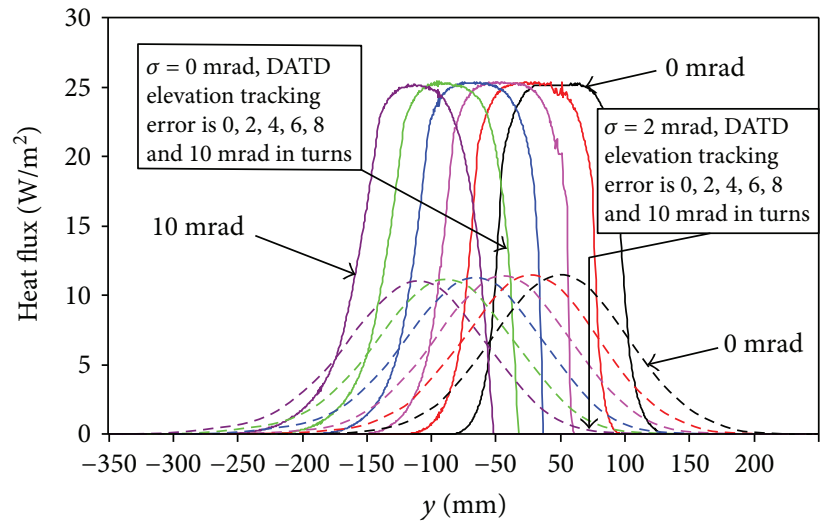

(a)

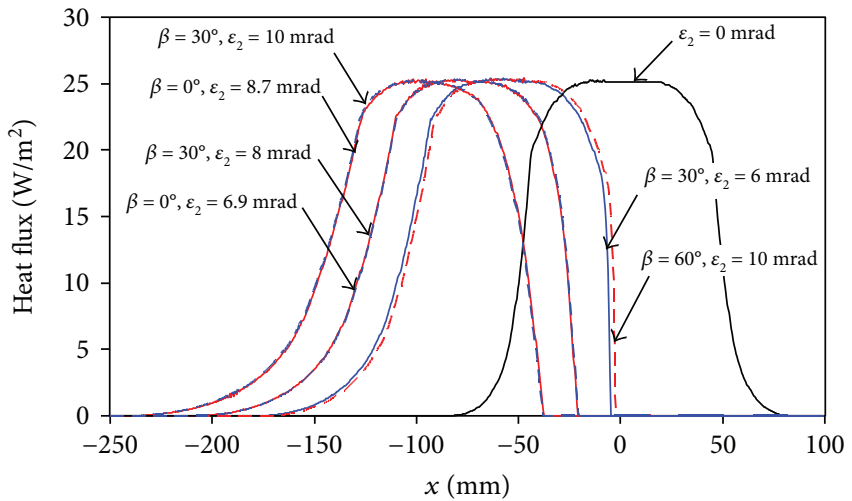

(b)

FIgURE 7: Influence of the EATD tracking error on the flux distribution of the focal plane.

Obviously, only when the angle $\beta=0$, then $\omega_{\text {err }}\left(\varepsilon_{1}, \varepsilon_{2}, 0\right)=$ $\sqrt{\left(\varepsilon_{2}\right)^{2}+\left(\varepsilon_{1}\right)^{2}}$, which is worth to be noticed.

The vanish-reduction effect produce essence is because the focal axis of the dish concentrator and the tracking axis of the EATD are not vertical. The intersection angle between the focal axis of the dish concentrator and azimuth tracking axis of the EATD is $\left(90^{\circ}-\beta\right)$ (Figure 2(b)). The vanishreduction effect is more obvious with the decrease of the angle $\left(90^{\circ}-\beta\right)$. Meanwhile, the influence of the elevation tracking error of the EATD on the dish concentrator was reduced. Due to the elevation tracking axis of the EATD always vertical to focal axis of the dish concentrator, there is no vanish-reduction effect in the elevation tracking error of the EATD transmission to the dish concentrator. Therefore, we could appropriately decrease the manufacture precision of the azimuth tracking device in the EATD to reduce production costs. Besides, it also could develop a new type of double-axis tracking device to increase the vanishreduction effect, such as a spin-elevation double-axis tracking device for dish concentrator system in Section 4.4. On the other hand, it is critical to evaluate or predict the long-term performance of the concentrator system $[14,15]$. If tracking error of the dish concentrator all comes from output angle error of the EATD, then according to the probability distribution of EATD output angle error model (based on statistical methods) and tracking error transmission law by 15 , we can evaluate the long-term performance of dish concentrator system, which will be our future research work.

4.2. Flux Distribution on the Focal Plane. In this paper, we take the typical $38 \mathrm{~kW}$ XEM-Dish system (Figure 1) as an example to study the effect of the tracking error of the EATD on the focal spot characteristics of the focal plane. The calculation parameters include concentrator radius $R_{1}=8.85 \mathrm{~m}$, focal length $f=9.49 \mathrm{~m}, \theta_{m}=30^{\circ}, R_{2}=0.9 \mathrm{~m}$, mirror reflectivity is 0.90 , absorption rate of the plane receiver is $100 \%$, DNI value $W_{0}=1000 \mathrm{~W} / \mathrm{m}^{2}, C_{t}=50$, mirror discrete parameter $K=275$, sun cone discrete parameter $W=201$, and total tracking rays are $1.46 \times 10^{9}$.

The influence of the tracking error of EATD on the flux curve and flux contour map of the focal spot are shown in Figures 7 and 8, respectively. From Figure 7(a), the movement and extent of the focal spot along the $y$-axis negative direction intensify with increase of the elevation tracking error of the EATD, but the flux peak value changes small. 


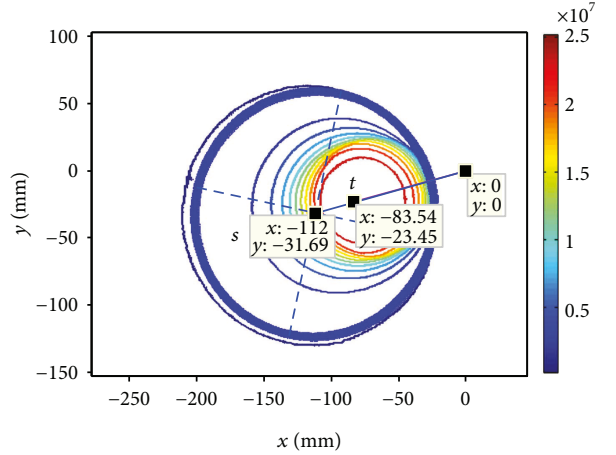

(a)

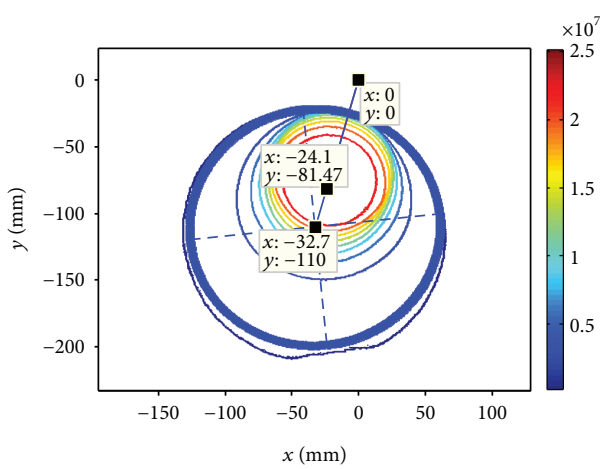

(c)

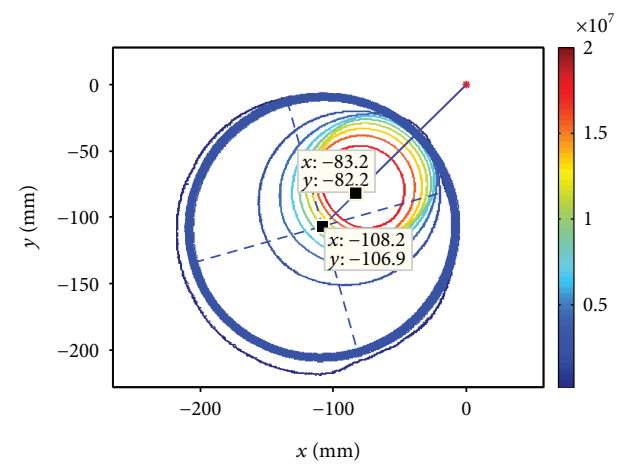

(e)

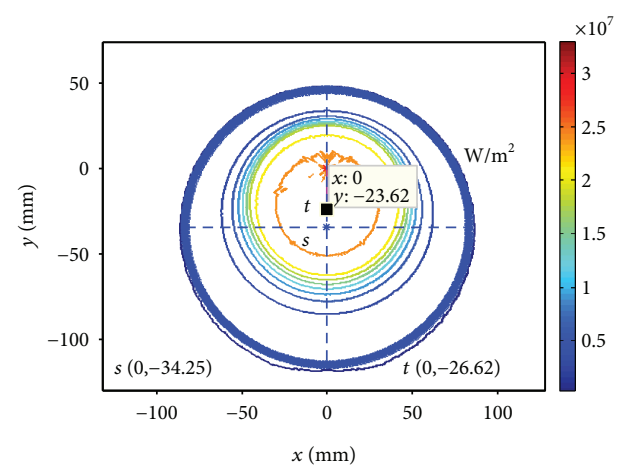

(g)

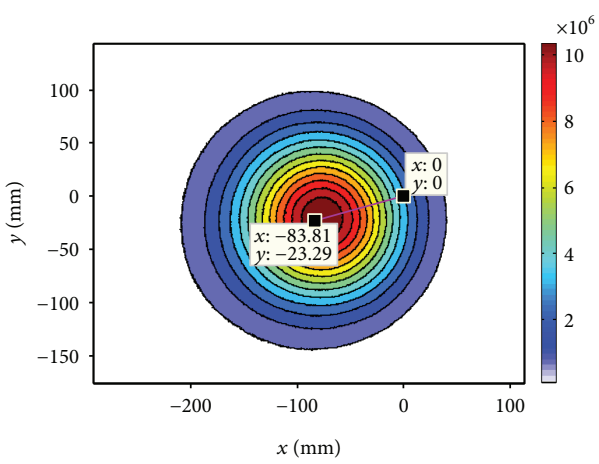

(b)

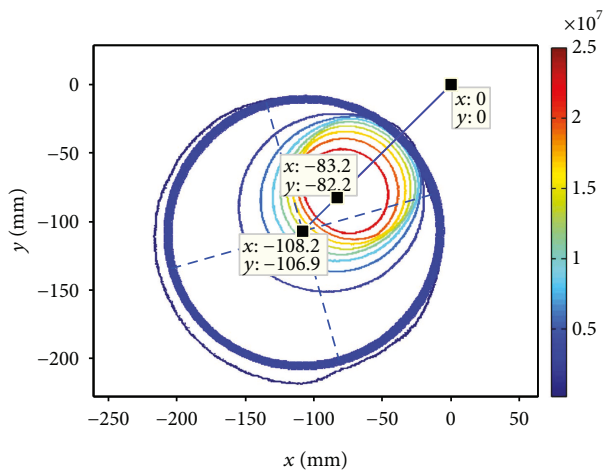

(d)

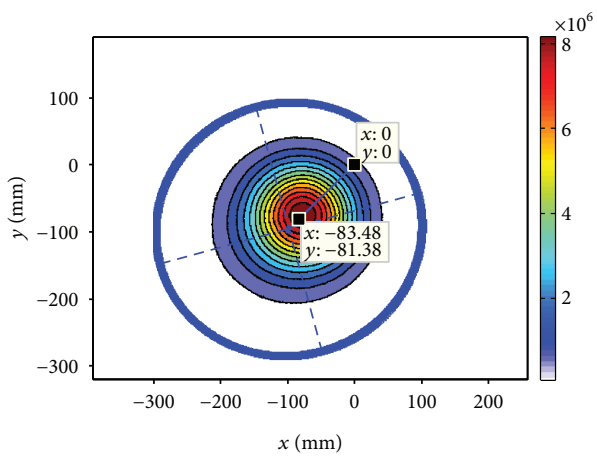

(f)

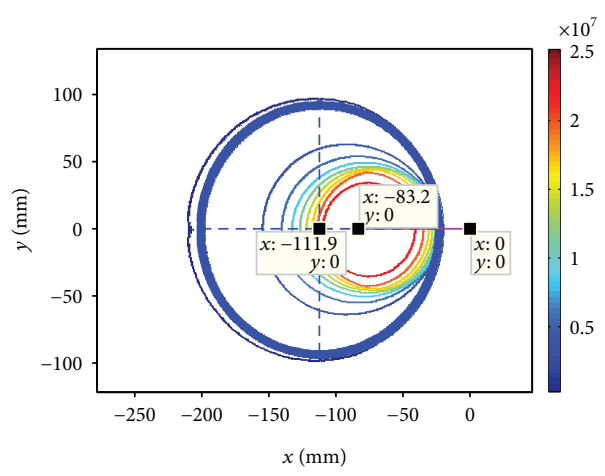

(h)

Figure 8: The flux distribution of the focal plane under the EATD tracking error (W/ $/ \mathrm{m}^{2}$ ). (a) $\sigma=0, \beta=30^{\circ}, \varepsilon_{1}=2 \mathrm{mrad}$, and $\varepsilon_{2}=8 \mathrm{mrad}$; (b) $\sigma=2 \mathrm{mrad}, \beta=30^{\circ}, \varepsilon_{1}=2 \mathrm{mrad}$, and $\varepsilon_{2}=8 \mathrm{mrad}$; (c) $\sigma=0, \beta=0^{\circ}, \varepsilon_{1}=6.9 \mathrm{mrad}$, and $\varepsilon_{2}=2 \mathrm{mrad} ;(\mathrm{d}) \sigma=0, \beta=0^{\circ}, \varepsilon_{1}=6.9 \mathrm{mrad}$, and $\varepsilon_{2}=6.9 \mathrm{mrad} ;$ (e) $\sigma=0, \beta=0^{\circ}, \varepsilon_{1}=6.9 \mathrm{mrad}, \varepsilon_{2}=6.9 \mathrm{mrad}$, and $W_{0}=800 \mathrm{~W} / \mathrm{m}^{2}$; (f) $\sigma=2 \mathrm{mrad}, \beta=0^{\circ}, \varepsilon_{1}=6.9 \mathrm{mrad}, \varepsilon_{2}=6.9 \mathrm{mrad}$, and $W_{0}=800 \mathrm{~W} / \mathrm{m}^{2}$; (g) $\sigma=0, \beta=0^{\circ}, \varepsilon_{1}=2 \mathrm{mrad}$, and $\varepsilon_{2}=0$; (h) $\sigma=0, \beta=0^{\circ}, \varepsilon_{1}=0, \varepsilon_{2}=6.9 \mathrm{mrad}$ or $\beta=30^{\circ}$, $\varepsilon_{1}=0$, and $\varepsilon_{2}=8 \mathrm{mrad}$. Note: only Figures $8(\mathrm{e})$ and $8(\mathrm{f})$ are with $W_{0}=800 \mathrm{~W} / \mathrm{m}^{2}$ and the other figures are with $W_{0}=1000 \mathrm{~W} / \mathrm{m}^{2}$. 


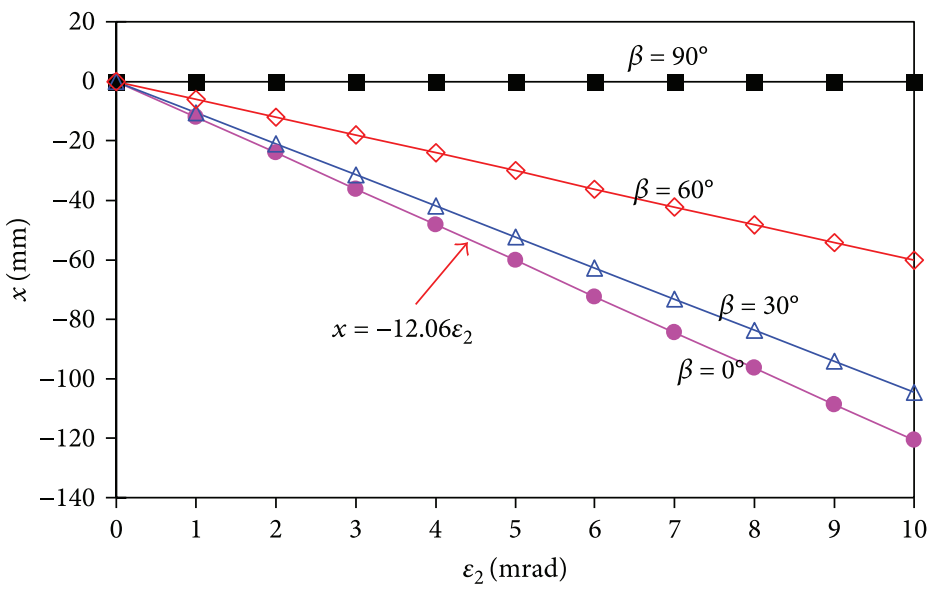

FIGURE 9: The relationship between the centroid movement distance of the focal spot and azimuth tracking error of the EATD.

Although the mirror slope error of the dish concentrator would increase the geometry size of the focal spot and decrease the flux peak value of the focal spot [24], it would not influence the centroid position of the focal spot. From the comparison of Figures 8(a) and 8(b) and Figures 8(e) and $8(\mathrm{f})$, respectively, we could clearly see that. The DNI value would only influence the flux density value of the focal spot [25] but would not influence the centroid position of the focal spot (comparison of Figures 8(d) and 8(e)). In conclusion, the centroid position of the focal spot on the focal plane depends on the tracking error of the dish concentrator but has nothing to do with the mirror slope error and DNI. Therefore, the centroid position of the focal spot on the focal plane could be used for estimate and calibration of the tracking error of the dish concentrator (Section 4.3).

The azimuth and elevation tracking error of the EATD only have influence on the centroid coordinates of the focal spot along $x$-axis and $y$-axis, respectively. For example, the coordinate of the focal spot centroid along $y$-axis is $-23.45 \mathrm{~mm}$ in both Figure 8 (a) $\left(\beta=30^{\circ}, \varepsilon_{1}=2 \mathrm{mrad}\right.$, and $\left.\varepsilon_{2}=8 \mathrm{mrad}\right)$ and Figure $8(\mathrm{~g})\left(\beta=0^{\circ}, \varepsilon_{1}=2 \mathrm{mrad}\right.$, and $\varepsilon_{2}=0 \mathrm{mrad}$ ); the coordinate of the focal spot centroid along $x$-axis is $-83.20 \mathrm{~mm}$ in Figure 8 (a) (double tracking error) and Figure $8(\mathrm{~h})$ (single tracking error); the azimuth and elevation tracking error of the EATD are all $6.9 \mathrm{mrad}(\beta=0)$ in Figures $8(\mathrm{~d})-8(\mathrm{f})$, so the coordinate of the focal spot centroid along $x$-axis and $y$-axis are the same $-83.2 \mathrm{~mm}$. These show that the influence of the azimuth and elevation tracking error of the EATD on the centroid position of the focal spot is independent. Moreover, the position of the point $g$ (Figure 2(b)) has no influence for the focal spot characteristics, that is, to say the EATD could be installed on every position in a dish concentration system and does not need to modify the tracking program of the EATD.

4.3. Centroid Moving Function and Intercept Factor. The functional relationship between the centroid movement distance of the focal spot on focal plane and EATD tracking error is called centroid movement function; this function could be used for evaluating and quantitatively calibrating the tracking error of the EATD. The influence curve of the azimuth tracking error of the EATD on the centroid movement distance is given in Figure 9. We can see that the movement distance of the focal spot centroid has linear relationship with the azimuth tracking error of the EATD. The centroid moving function is $x=-12.06 \varepsilon_{2}$ and $y=-12.06 \varepsilon_{1}$ when the elevation angle of the dish concentrator is $0^{\circ}$. Considering the vanish-reduction effect, the centroid movement function of the focal spot in $38 \mathrm{~kW}$ XEM-Dish system is as follows:

$$
\begin{aligned}
& x=-12.06 \operatorname{arcos}\left[\cos ^{2}(90-\beta) \cdot\left(1-\cos \varepsilon_{2}\right)+\cos \varepsilon_{2}\right], \\
& y=-12.06 \varepsilon_{1} .
\end{aligned}
$$

Noteworthiness, the simplified formula $y=-f \times \tan \left(\varepsilon_{1}\right)$ is usually not equal to (16). For example, when the $\varepsilon_{1}=10 \mathrm{mrad}$, the centroid movement distance is $-120.60 \mathrm{~mm}$ calculated by (16), while $y=-f \times \tan \left(\varepsilon_{1}\right)=-9490 \times \tan (0.010)=-94.90 \mathrm{~mm}$ and there is $25.70 \mathrm{~mm}$ difference between them. Therefore, the centroid movement function of the focal spot on focal plane needs to be accurately determined by ray tracing method.

The centroid movement function is used to guide the calibration of the tracking error of the dish concentrator system as the following: measuring the focal spot on the focal plane in the dish concentrator system and extracting the centroid coordinates of the focal spot; adopting the centroid coordinates to calculate the double-axis tracking error of the EATD by (16) and then calibrating the tracking error of the dish concentrator. Of note, the assessment and calibration of the tracking error of the dish concentrator system are not suitable for the large working elevation angle occasion (especially close to the elevation angle is $90^{\circ}$ ). Because the vanishreduction effect is becoming intense during this time, it would lead the centroid movement distance of the focal spot along the $x$-axis to be too small to be discovered. For example, the centroid movement distance of the focal spot equals $0 \mathrm{~mm}$ when the working elevation $\beta$ equals $90^{\circ}$ (Figure 9), so the effect of the azimuth tracking error of the EATD on the dish concentrator is completely covered, but this effect appears again after the working elevation angle $\beta$ decreases such as $\beta=30^{\circ}$. 


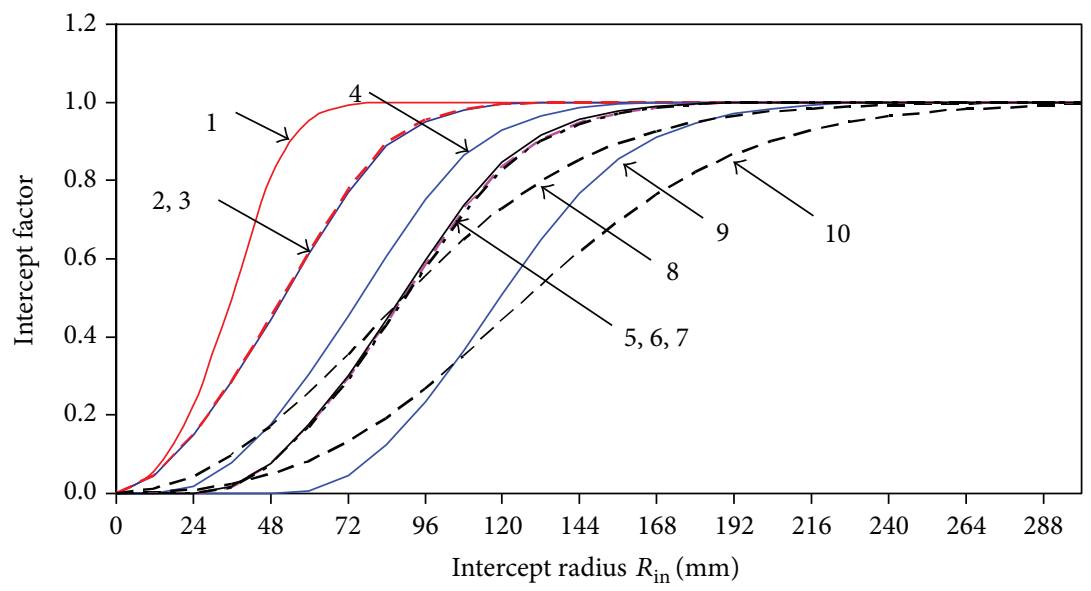

FIGURE 10: Influence of the EATD tracking error and mirror slope error on the intercept factor. $1: w_{\text {err }}=0 ; 2: \beta=0^{\circ}, \varepsilon_{1}=3.6, \varepsilon_{2}=0, w_{\text {err }}=3.6$; $3: \beta=0^{\circ}, \varepsilon_{1}=3, \varepsilon_{2}=2, w_{\mathrm{err}}=3.6 ; 4: \beta=0^{\circ}, \varepsilon_{1}=6, \varepsilon_{2}=0 ; 5: \beta=30^{\circ}, \varepsilon_{1}=2, \varepsilon_{2}=8, w_{\mathrm{err}}=7.184 ; 6: \beta=0^{\circ}, \varepsilon_{1}=3.95, \varepsilon_{2}=6, w_{\mathrm{err}}=7.184 ; 7: \beta=0^{\circ}$, $\varepsilon_{1}=7.184, \varepsilon_{2}=0 ; 8: \beta=0^{\circ}, \varepsilon_{1}=6, \varepsilon_{2}=0, \sigma=2 ; 9: \beta=0^{\circ}, \varepsilon_{1}=10, \varepsilon_{2}=0 ; 10: \beta=0^{\circ}, \varepsilon_{1}=10, \varepsilon_{2}=0, \sigma=2$. Note: only curve 10 and 14 have the mirror slope error of $\sigma=2 \mathrm{mrad}$, other curves have the mirror slope error of $\sigma=0 \mathrm{mrad}$.

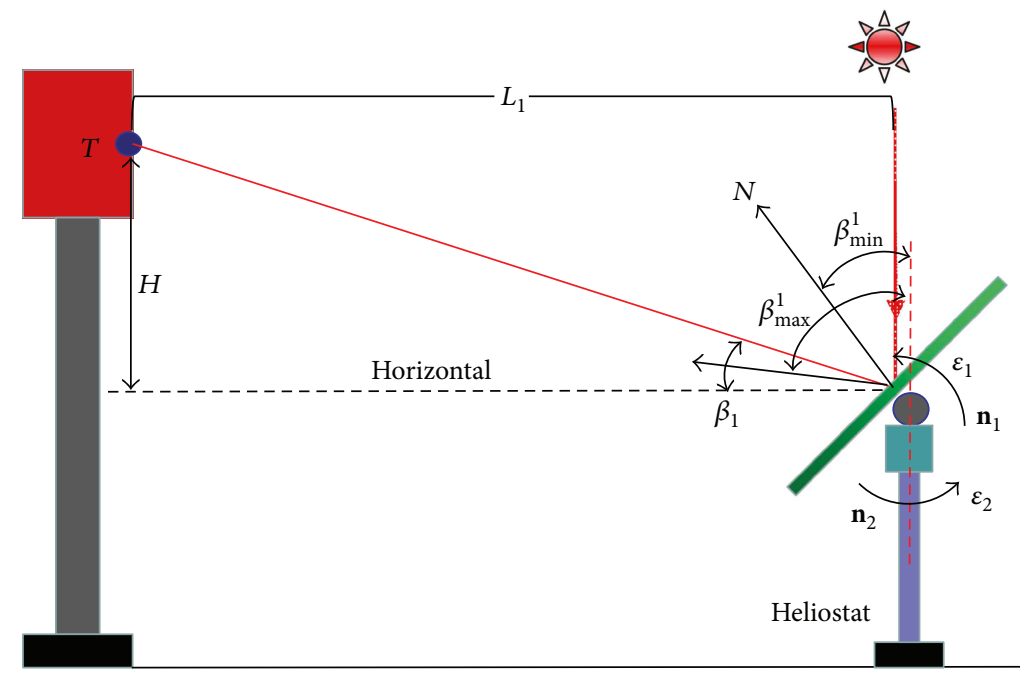

FIgURE 11: A schematic diagram of the elevation-azimuth double-axis tracking of a heliostat in a tower plant.

The double-axis tracking error of the EATD and mirror slope error has significant influence on the intercept factor (Figure 10). When the influence of the EATD tracking error only exists, the intercept factor curve would be the same as long as the total tracking error $\omega_{\text {err }}$ of the dish concentrator is the same. Although the single tracking error of the EATD is different, such as curve 5, 6, and 7 in Figure 10, the intercept factor curves are the same. Another example is curve 2 and 3 which are the same.

4.4. Application of the Vanish-Reduction Effect. The solar heliostat in tower power plant also adopts the EATD [9] as shown in Figure 11. The characteristic axis of the heliostat is the mirror normal vector $\mathbf{N}$, and azimuth tracking axis of the EATD is vertical to the ground level. Thus, the intersection angle between the characteristic axis $\mathbf{N}$ and azimuth tracking axis of the EATD attains the maximum and minimum when the solar elevation angle $\beta$ is $0^{\circ}$ and $90^{\circ}$, respectively, given by (17), where the intersection angle $\beta_{1}$ between the reflection ray (aimed at target point on the receiver tower) and horizontal plane satisfied $\tan \left(\beta_{1}\right)=H / L_{1} ; H$ is the height between the target point and heliostat center; $L_{1}$ is horizontal distance between the target point and heliostat center. The angle $\beta_{1}$ increases with the decrease of the distance between the heliostat and the receive tower, and the angle $\beta_{\min }^{1}$ and $\beta_{\max }^{1}$ will decrease at the same time, which could increase the vanishreduction effect in the azimuth tracking error of the EATD transmit to heliostat for improving the tracking performance of the heliostat. According to this regulation, on the basis of guarantying the tracking accuracy of the heliostat, this could decrease the manufacturing cost of the heliostat according to gradual or gradient increase of the precision requirements of the azimuth tracking device in the EATD near or far from the receiver tower. 


$$
\begin{aligned}
& \beta_{\min }^{1}=0.5\left(90^{\circ}-\beta_{1}\right) \text { if } \beta=90^{\circ}, \\
& \beta_{\max }^{1}=90^{\circ}-0.5 \beta_{1} \text { if } \beta=0^{\circ} .
\end{aligned}
$$

In order to increase the vanish-reduction effect to reduce the effect of the tracking error of the double-axis device on the dish concentrator, a dish concentrator system using a spin-elevation double-axis tracking device (SETD) is proposed (Figure 12). The spin-elevation double-axis tracking was put forward by Chen et al. [8] and they defined the spin axis is a line between the heliostat center and fixed target and the elevation tracking axis in the SETD vertical to the spin axis. The SETD is widely used in the solar concentrator field where the solar concentrator can move but the heat absorber receiver is fixed [29]. However, the dish concentrator and receiver move together in the dish concentrator system and there is no fixed target in this system. Thus, we defined any direction as the spin axis. In Figure 12, angle $\beta_{2}$ is the inclination between the azimuth tracking axis of the SETD and horizontal plane. The spin tracking error $\varepsilon_{2 r}$ of the dish concentrator caused by spin tracking error of the SETD transmission to the dish concentrator could be calculated by (18). From Figure 13, we could clearly see that the error $\varepsilon_{2 \mathrm{r}}$ reduced to $0 \mathrm{mrad}$ first and then increased with the increase of the working elevation angle $\beta$ of the dish concentrator, and the error $\varepsilon_{2 \mathrm{r}}$ equals $0 \mathrm{mrad}$ when the angle $\beta$ equals to the inclination angle $\beta_{2}$. Therefore, selecting the appropriate angle $\beta_{2}$ could make the vanish-reduction effect adopt the SETD's obvious intensity than the EATD during the tracking error transmission, in order to increase the influence of the tracking error of the tracking device on the dish concentrator. Such as the angle $\beta_{2}=60^{\circ}$ in Figure 13, within the elevation angle $\beta$ range of $0^{\circ} \sim 75^{\circ}$, the spin tracking error $\varepsilon_{2 \mathrm{r}}$ of the dish concentrator adopted the SETD form obviously less than the EATD (i.e., $\beta_{2}=90^{\circ}$ ). Thus, appropriately reducing the manufacture precision requirements of the spin tracking device in SETD could decrease the manufacturing cost.

$$
\varepsilon_{2 \mathrm{r}}\left(\beta_{2}, \beta\right)=\operatorname{arcos}\left[\cos ^{2}\left(\beta-\beta_{2}\right) \cdot\left(1-\cos \varepsilon_{2}\right)+\cos \varepsilon_{2}\right] .
$$

\section{Conclusion}

In this paper, a flux distribution model of the focal plane of a dish concentrator system has been developed based on ray tracking method for researching the effect of the mirror surface slope error, DNI and EATD tracking error on the focal spot characteristics, and the error transmission law of the tracking error of the double-axis tracking device transmission to dish concentrator system. The main conclusions are as follows:

(1) The azimuth tracking error $\varepsilon_{2 \mathrm{r}}$ of the dish concentrator is transmitted by the azimuth tracking error $\varepsilon_{2}$ of the EATD. When the error $\varepsilon_{2}$ is constant, the error $\varepsilon_{2 \mathrm{r}}$ decreases with the increase of the working elevation angle $\beta$ of the dish concentrator and the error $\varepsilon_{2 \mathrm{r}}$ equals to $0 \mathrm{mrad}$ when $\beta=90^{\circ}$. We call this phenomenon the called vanish-reduction effect in tracking error transmission. The vanish-reduction

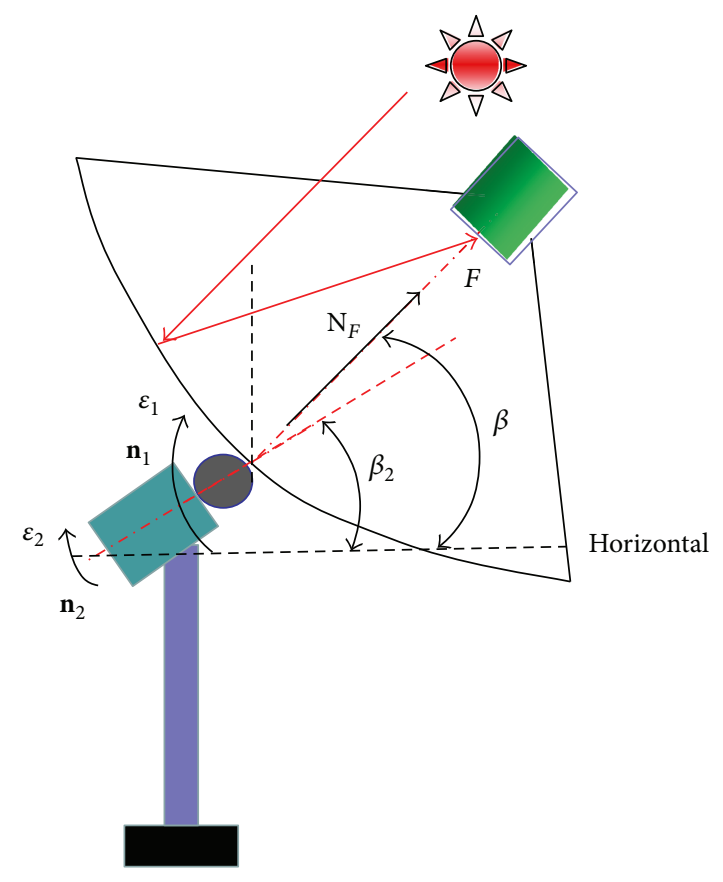

Figure 12: A schematic diagram of the spin-elevation double-axis tracking in dish concentrator system.

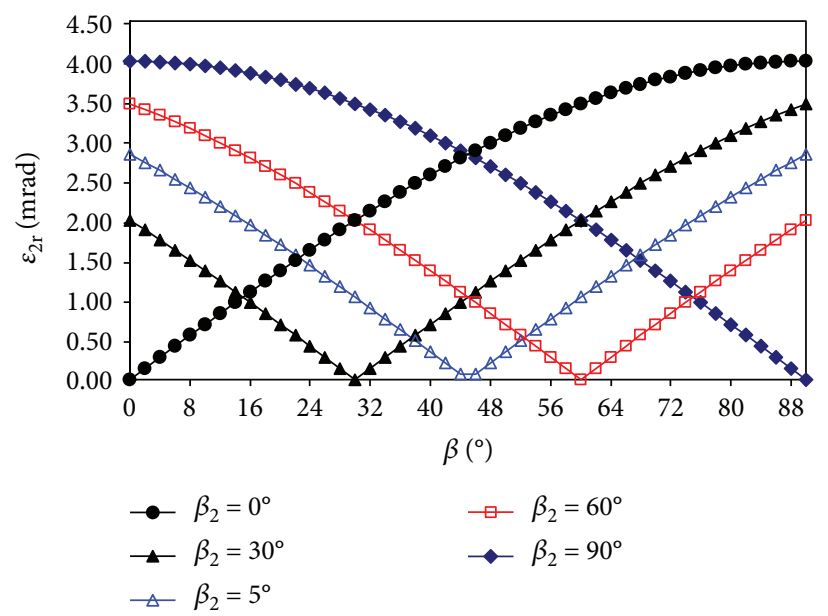

FIgURE 13: Error transmission law of the tracking error of the spin axis transmission to dish concentrator (spin axis tracking error is $4.0 \mathrm{mrad})$.

effect-produced essence is caused by the nonvertical of the focal axis being nonvertical to the dish concentrator and tracking axis of the EATD, and the vanish-reduction effect is increased with the decrease of the nonvertical angle, which could improve the tracking accuracy of the dish concentrator. Due to the elevation tracking axis of the EATD always vertical to the focal axis, the elevation tracking error of the dish concentrator equals to the elevation tracking error of the EATD. In addition, the intercept factor only depends on the total tracking error of the dish concentrator when only considering the tracking error. 
(2) The centroid position of the focal spot on the focal plane depends on the tracking error of the dish concentrator without the effects of the mirror slope error and DNI. Only the azimuth tracking error and elevation tracking error of the EATD have influence on the centroid's movement distance of the focal spot along $x$-axis and $y$-axis, respectively, and the centroid's moving distance has linear function relationship with the EATD tracking error. For $38 \mathrm{~kW}$ XEM-Dish system, the centroid's moving function is $x=-12.06 \varepsilon_{2 \mathrm{r}}$ and $y=-12.06 \varepsilon_{1}$. This function could be used to evaluate and quantitative calibration of the tracking error of the dish concentrator system but is not suitable for the large working elevation angle occasion.

(3) The vanish-reduction effect also exists in the azimuth tracking error of the EATD transmission to the solar heliostat. Through decreasing the distance between the heliostat and receiver tower, increasing the height of the receiver tower and solar elevation angle could increase the vanish-reduction effect in order to improve the tracking performance of the heliostat. Besides, a dish concentrator system using a spinelevation double-axis tracking device (SETD) is proposed, which could increase the influence of the spin tracking error of the SETD on the dish concentrator system and improve the tracking performance of the dish concentrator system.

\section{Nomenclature}

$A_{k m}: \quad$ Daylighting area of the mirror grid $\mathrm{km}\left(\mathrm{m}^{2}\right)$

$f: \quad$ Focal length of the dish concentrator (m)

$K, M$ : Discretion numbers of the dish concentrator mirror

$N, W$ : Discretion numbers of the sun cone

$R_{1}$ : $\quad$ Radius of the dish concentrator (m)

$R_{2}$ : Void field radius of the dish concentrator $(\mathrm{m})$

$W_{0}$ : $\quad$ DNI value $\left(\mathrm{Wm}^{-2}\right)$

$w_{\text {err }}$ : Total tracking error of the dish concentrator (mrad), $w_{\text {err }}=\sqrt{\left(\varepsilon_{2 r}\right)^{2}+\left(\varepsilon_{1}\right)^{2}}$.

Greek symbols

$\delta$ : Solar half angle (mrad)

$\sigma: \quad$ Standard deviation of the mirror slope error (mrad)

$\varepsilon_{1}$ : Elevation tracking error of the EATD (mrad)

$\varepsilon_{2}$ : Azimuth tracking error of the EATD (mrad)

$\varepsilon_{2 \mathrm{r}}$ : Azimuth angle or spin angle tracking error of the dish concentrator (mrad)

$\beta$ : Concentrator working elevation angle (degrees)

$\beta_{1}$ : The intersection angle between the reflection ray (at heliostat center) and the horizontal plane (degrees)

$\beta_{2}$ : Angle between spin axis and horizontal plane (degrees) $\theta_{m}$ : Lack angle of the dish concentrator (degrees).

\section{Abbreviations}

EATD: Elevation-azimuth double-axis tracking device DNI: Direct normal irradiation.

\section{Subscripts}

$\mathrm{km}$ : Concentrator mirror grid at position $(k, m)$

$w n$ : Sun cone grid at position $(w, n)$.

\section{Conflicts of Interest}

The authors declare that there is no conflicts of interest regarding the publication of this paper.

\section{Acknowledgments}

This work is supported by the National Natural Science Foundation of People's Republic of China (nos. 51576061 and 51641504), Hunan Provincial Natural Science Foundation of China (no. 2016JJ2052), and Hunan Province Postgraduate Innovation Project Foundation of People's Republic of China (nos. CX2016B549 and CX2017B628).

\section{References}

[1] H. Sayyaadi and M. S. Boroujeni, "Conceptual design, process integration, and optimization of a solar $\mathrm{Cu}-\mathrm{Cl}$ thermochemical hydrogen production plant," International Journal of Hydrogen Energy, vol. 42, no. 5, pp. 2771-2789, 2017.

[2] L. Nkhonjera, T. Bello-Ochende, G. John, and C. K. King'ondu, "A review of thermal energy storage designs, heat storage materials and cooking performance of solar cookers with heat storage," Renewable and Sustainable Energy Reviews, vol. 75, pp. 157-167, 2017.

[3] D. A. Baharoon, H. A. Rahman, W. Z. W. Omar, and S. O. Fadhl, "Historical development of concentrating solar power technologies to generate clean electricity efficiently - a review," Renewable and Sustainable Energy Reviews, vol. 41, pp. 9961027, 2015.

[4] Y. Qiu, Y. L. He, M. Wu, and Z. J. Zheng, "A comprehensive model for optical and thermal characterization of a linear Fresnel solar reflector with a trapezoidal cavity receiver," Renewable Energy, vol. 97, pp. 129-144, 2016.

[5] G. Li and Y. Jin, "Optical simulation and experimental verification of a Fresnel solar concentrator with a new hybrid second optical element," International Journal of Photoenergy, vol. 2016, Article ID 4970256, 8 pages, 2016.

[6] F. Chen, M. Li, R. Hassanien Emam Hassanien et al., "Study on the optical properties of triangular cavity absorber for parabolic trough solar concentrator," International Journal of Photoenergy, vol. 2015, Article ID 895946, 9 pages, 2015.

[7] J. Wang, J. Wang, X. Bi, and X. Wang, "Performance simulation comparison for parabolic trough solar collectors in China," International Journal of Photoenergy, vol. 2016, Article ID 9260943, 16 pages, 2016.

[8] Y. T. Chen, K. K. Chong, T. P. Bligh et al., "Non-imaging, focusing heliostat," Solar Energy, vol. 71, no. 3, pp. 155-164, 2001.

[9] O. Behar, A. Khellaf, and K. Mohammedi, "A review of studies on central receiver solar thermal power plants," Renewable and Sustainable Energy Reviews, vol. 23, pp. 12-39, 2013.

[10] J. Coventry and C. Andraka, "Dish systems for CSP," Solar Energy, vol. 152, pp. 140-170, 2017.

[11] H. Ma, G. Jin, X. Zhong, K. Xu, and Y. Li, "Optical design of a solar dish concentrator based on triangular membrane facets," 
International Journal of Photoenergy, vol. 2012, Article ID 391921, 5 pages, 2012.

[12] Q. Mao, L. Zhang, and H. Wu, "Study on concentrating characteristics of a solar parabolic dish concentrator within high radiation flux," International Journal of Photoenergy, vol. 2015, Article ID 787280, 7 pages, 2015.

[13] I. Reda and A. Andreas, "Solar position algorithm for solar radiation applications," Solar Energy, vol. 76, no. 5, pp. 577589, 2004.

[14] R. O. Hughes, "Effects of tracking errors on the performance of point focusing solar collectors," Solar Energy, vol. 24, no. 1, pp. 83-92, 1980.

[15] V. Badescu, "Different tracking error distributions and their effects on the long-term performances of parabolic dish solar power systems," International Journal of Solar Energy, vol. 14, no. 4, pp. 203-216, 1994.

[16] V. Badescu, "Theoretical derivation of heliostat tracking errors distribution," Solar Energy, vol. 82, no. 12, pp. 1192-1197, 2008.

[17] Y. Hu and Y. Yao, "Optical analysis and output evaluation for a two-stage concentration photovoltaic system by using Monte Carlo ray-tracing method," Optik-International Journal for Light and Electron Optics, vol. 131, pp. 713-723, 2017.

[18] K. Shanks, N. Sarmah, J. P. Ferrer-Rodriguez et al., "Theoretical investigation considering manufacturing errors of a high concentrating photovoltaic of cassegrain design and its experimental validation," Solar Energy, vol. 131, pp. 235245, 2016.

[19] X. L. Xia, G. L. Dai, and Y. Shuai, "Experimental and numerical investigation on solar concentrating characteristics of a sixteen-dish concentrator," International Journal of Hydrogen Energy, vol. 37, no. 24, pp. 18694-18703, 2012.

[20] H. Li, W. Huang, F. Huang, P. Hu, and Z. Chen, "Optical analysis and optimization of parabolic dish solar concentrator with a cavity receiver," Solar Energy, vol. 92, pp. 288-297, 2013.

[21] L. S. M. Castellanos, G. E. C. Caballero, V. R. M. Cobas et al., "Mathematical modeling of the geometrical sizing and thermal performance of a dish/Stirling system for power generation," Renewable Energy, vol. 107, pp. 23-35, 2017.

[22] G. Johnston, "Focal region measurements of the $20 \mathrm{~m} 2$ tiled dish at the Australian National University," Solar Energy, vol. 63, no. 2, pp. 117-124, 1998.

[23] S. Ulmer, W. Reinalter, P. Heller et al., "Beam characterization and improvement with a flux mapping system for dish concentrators," in ASME Solar 2002: International Solar Energy Conference, pp. 285-292, Reno, NV, USA, 2002.

[24] H. Lee, "The geometric-optics relation between surface slope error and reflected ray error in solar concentrators," Solar Energy, vol. 101, pp. 299-307, 2014.

[25] Q. Mao, Y. Shuai, and Y. Yuan, "Study on radiation flux of the receiver with a parabolic solar concentrator system," Energy Conversion and Management, vol. 84, pp. 1-6, 2014.

[26] M. H. Tan and K. K. Chong, "Influence of self-weight on electrical power conversion of dense-array concentrator photovoltaic system," Renewable Energy, vol. 87, pp. 445-457, 2016.

[27] M. M. Elsayed, K. A. Fathalah, and O. M. Al-Rabghi, "Measurements of solar flux density distribution on a plane receiver due to a flat heliostat," Solar Energy, vol. 54, no. 6, pp. 403-411, 1995.
[28] S. M. Jeter, "The distribution of concentrated solar radiation in paraboloidal collectors," Journal of Solar Energy Engineering, vol. 108, no. 3, pp. 219-225, 1986.

[29] B. H. Lim, K. K. Chong, C. S. Lim, and A. C. Lai, "Latitudeorientated mode of non-imaging focusing heliostat using spinning-elevation tracking method," Solar Energy, vol. 135, pp. 253-264, 2016. 

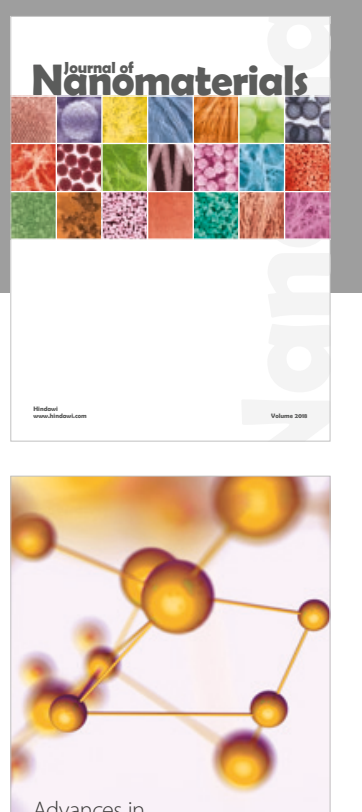

Physical Chemistry
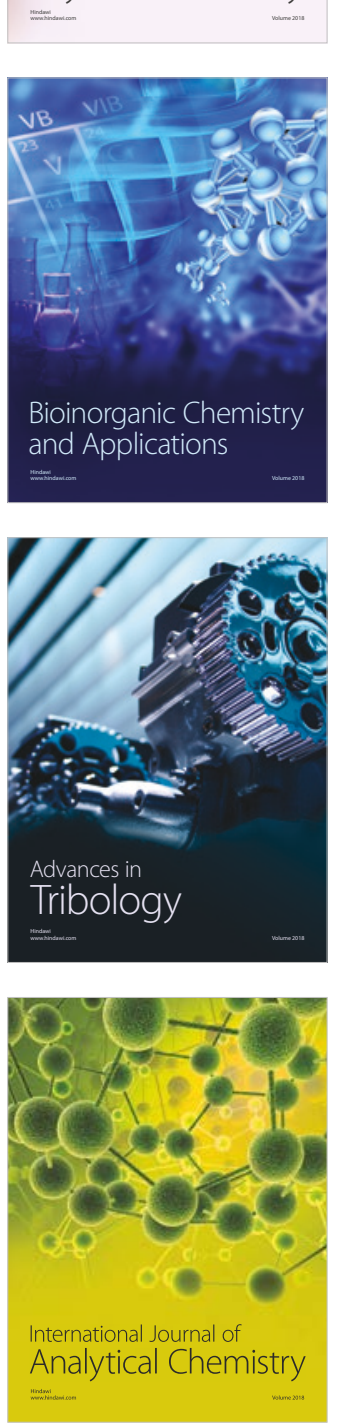

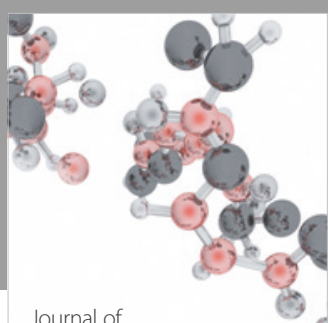

Analytical Methods

in Chemistry

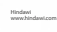

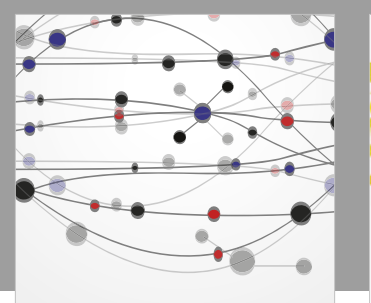

The Scientific World Journal

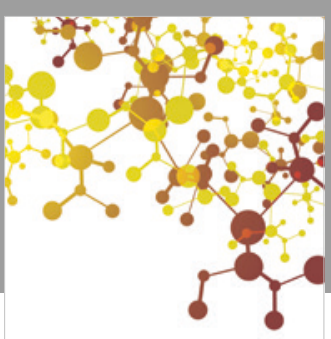

Journal of

Applied Chemistry
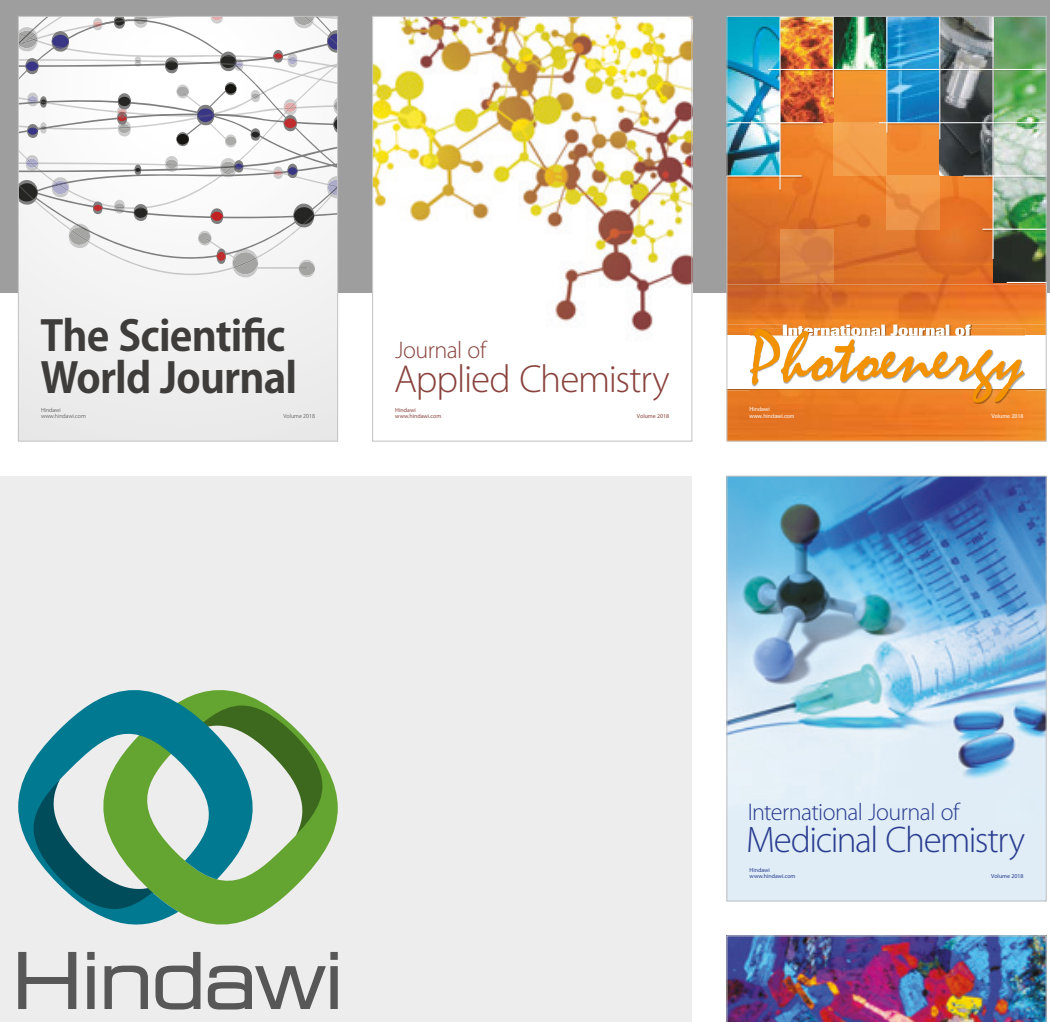

Submit your manuscripts at

www.hindawi.com
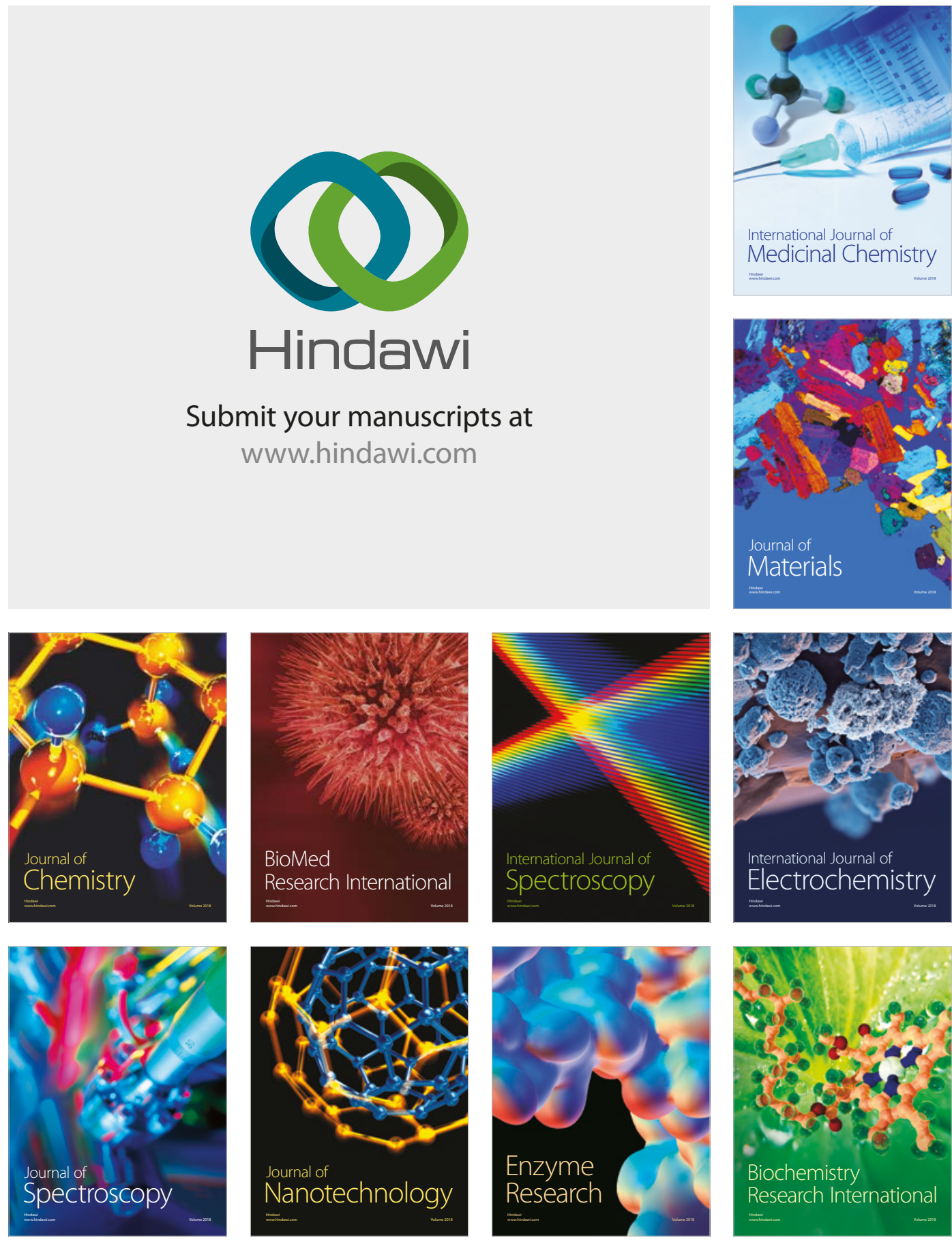
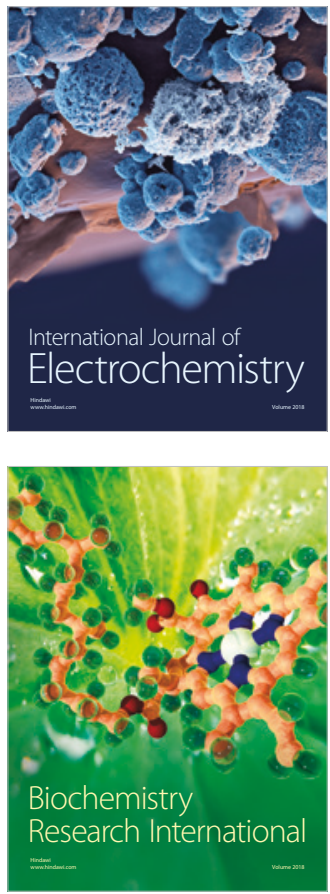